\title{
Leukemie by Kinders
}

\author{
M.J. Hugo, B. Verpleegkunde (Stellenbosch), \\ Studeer tans vir graad M. Cur. Universiteit van Pretoria. \\ A. Botha, B. Cur (Pretoria), \\ Studeer tans vir graad M. Cur. Universiteit van Pretoria.
}

\section{SUMMARY}

Leucaemia is a major cause of death in children between the ages of one and fourteen years.

Only a team whose members work well together can care effectively for a child with leucaemia, and of the team the nurse is one of the most important members.

In order to maintain her place in the team it is essential for the nurse to keep up to date with the latest developments in the treatment of this formerly fatal illness.

'n Groot oorsaak van sterfte by kinders is leukemie. Dié siekte veroorsaak, naas ongelukke, die tweede meeste sterfte by kinders tussen die ouderdom van een en veertien jaar.

\section{Patogenese}

'n Maligne proliferasie van die voorgangerselle in die bloed vind plaas en dit tas veral die beenmurg, maar verder ook die perifere bloed en ander sagte weefsel, byvoorbeeld die retikulo-endoteel stelsel aan.

Die siekte word verdeel in 'n akute en 'n chroniese tipe. By die akute tipe is daar primitiewe voorloperselle (blaste) wat prolifereer en as dit onbehandeld bly, is dit gou noodlottig. Die kenmerk van die chroniese tipe is dat daar meer van die ryper tipes voorloperselle, byvoorbeeld miëlosiete is.

Kinders, in teenstelling met volwassenes, kry meer algemeen die akute tipe leukemie. Van alle leukemie-gevalle by kinders is ongeveer $80 \%$ die akute limfoblastiese tipe, $8 \%$ is die akute miëloblastiese tipe; $8 \%$ die akute monositiese tipe en die res is ander vorme van leukemie. Soms onstaan akute limfoblastiese leukemie as gevolg van leukemiese transformasie van limfosarkome af - dit vind by $30 \%$ van kinders met hierdie toestand plaas 2, p.319, Aaangesien die oorgrote meerderheid van kinders akute limfoblastiese leukemie kry, sal die res van die bespreking, om praktiese redes, net daaraan gewy word.

\section{Voorkoms van leukemie by kinders}

Die voorkoms van leukemie (spesifiek akute limfoblastiese leukemie) styg vanaf tweejarige ouderdom en bereik 'n piek by vyfjaar, waarna dit weer daal soos die ouderdom toeneem. Tot tweejaar is daar \pm 25 gevalle per miljoen van die hele bevolking en tussen 3-5 jaar \pm 50 gevalle per miljoen. ${ }^{10}-$ Eweveel seuns en dogters kry die siekte en by babas is dit skaars.

\section{Etiologie}

Leukemie word by diere opgewek deur sekere virusse, chemiese karsinogene en bestraling. Oorertlike faktore kan saam met bogenoemde agense 'n rol speel om 'n dier meer vatbaar vir leukemie te maak.

By die mens is die werklike oorsaak van leukemie nog onbekend. Die oorsaak is waarskynlik multifaktoriaal met bestraling, infeksies en omgewingsfaktore saam met konstitusionele en genetiese eienskappe wat 'n definitiewe rol speel.

\section{Kliniese Beeld}

Die klassieke simptome wat 'n akute limfoblastiese leukemie toon kan toegeskryf word aan anemie, trombositopenie en neutropenie. So 'n pasiënt is bleek, lusteloos, kortasem en koorsig. Omdat trombositopenie teenwoordig is, is daar bloedings van die slymvliese en kneusplekke. Daar kan verder hematurie, rektale bloedings of bloeding in enige orgaan wees. Die gevolg van die neutropenie is dat so " pasiënt 'n verhoogde vatbaarheid vir infeksie het en die organismes kan bakterieë, swamme of virusse wees. Infeksies van die mond en keel is veral algemeen.

Vergrote limfkliere kom by \pm 'n derde van gevalle voor, asook vergrote milt en lewer, maar dié is selde massiel vergroot. Beenaantasting is baie algemeen met beenpyn dikwels in die langbene en teerheid by die sternum. Daar is subperiosteale bloedings asook effusies in gewrigte. Die beenpyn kan veroorsaak dat die kind nie wil beweeg of loop nie en dié beeld kan met akute osteomiëlitis verwar word.

Indien daar aantasting van die meninges is, braak die kind en hy het hoofpyn, maar dié toestand moet onderskei word van bakteriële meningitis. Sodanige aantasting kom gewoonlik eers later in die verloop van die siekte voor. 
By akute miëloblastiese leukemie kom chloromata voor dit is versamelings van leukemiese weefsel wat tumore vorm. Dit kom dikwels in die oogkas voor, maar word ook in ander organe gevind.

\section{Diagnose}

Diagnose word gemaak na 'n noukeurige kliniese ondersoek, maar spesiale ondersoeke is onontbeerlik om die diagnose te bevestig. Van hierdie ondersoeke is ' $n$ volbloedtelling en beenmurgaspirasie die belangrikste.

Die perifere bloed sal anemie, 'n lae hemoglobien, trombositopenie, lae plaatjietelling, neutropenie en lae witbloedseltelling bevestig. Teenwoordigheid van sirkulende blastselle is diagnosties saam met 'n beemurg-aspirasie wat sal toon dat normale beenmurgelemente deur blaste verdring is. Soms word geen blaste in die perifere bloed gesien nie, en dan word van aleukëmiese leukemie gepraat. Blastselle kan wissel van geen tot 100000 per $\mathrm{mm}^{3}$ in die perifere bloedtelling. ${ }^{10}$.

Om tussen die tipes leukemie te kan onderskei, word spesiale kleurings van blastselle in die beenmurgaspiraat gedoen en verder is die morfologiese voorkoms van die selle ook vir dié doel belangrik. Ten spyte van die genoemde onderskeidingsmetodes, kan sommige nie geklassifiseer word nie en word onklassifiseerbaar genoem.

\section{Differensiële Diagnose}

Met goeie bloed- en beenmurgondersoeke kan daar selde twyfel oor die diagnose wees. Foute word gemaak wanneer die dokter nie aan die diagnose dink nie en daarom nie die nodige toetse aanvra nie.

Siektes wat leukemie kan "naboots" is rumatiekkoors, infektiewe endokarditis, ostemiëlitis, tuberkulose en meningitis. Difterie, tifoiëdkoors en brusellose kan ook verwarring skep. As gevolg van die beenmurginfiltrasie by neuroblastoom en limfone, lyk dit ook soos leukemie. Klierkoors is 'n algemene diagnostiese "lokval" wat met die nodige toetse uitgeskakel kan word.

\section{Behandeling van leukemie}

Voor sitostatika gebruik is, was daar nie "n doeltreffende behandeling vir leukemie nie. Alleen ondersteunende behandeling deur middel van antibiotika en bloedoortapping is gegee. Die prognose by kinders het heelwat verbeter met die gebruik van sitostatika en beter ondersteunende behandeling. Vooruitsigte t.et verbeter, ondat daar beter isolasie-fasiliteite, antibiotika, profilaktiese terapie om komplikasies te verminder, is, meer kennis van die siekte en sentra met personeel wat belangstel in die leukemiese pasiënte en goed opgelei is om hulle te versorg.

Dit is verkieslik dat leukemiese kinders by gespesialiseerde, toegeruste sentra behandeling sal ontvang, want daar kry hulle nie alleen die beste behandeling nie, maar die geleentheid is ook daar beskikbaar om 'n deeglike studie van hulle siekte en die gepaardgaande komplikasies te maak.

Die konsep dat leukemie ongeneeslik is het verander. Dit is nou 'n siekte waar genesing moontlik is, indien toepaslike aggressiewe behandeling vroeg in die verloop van die siekte toegepas word en opvolg-behandeling volgehou word totdat alle leukemieselle in die liggaam vernietig is. Met die nuutste metodes kan verwag word dat $50 \%$ van kinders met leukemie genees kan word. 5 pp.17-41.

Die benadering in die behandeling van leukemie kan as volg opgesom word:-

1. Induksie met chemoterapeutiese middels vir remissie van siekte.

2. Uitwissing van die oorblywende siekte met:

(a) aanhoudende intensiewe kombinasie-chemoterapie

(b) radioterapiebehandeling vir anatomiese dele wat nie effektief met chemoterapie bereik word nie.

3. Toepaslike ondersteunende terapie.

4. Opsporing en vroeë behandeling van komplikasies.

Die induksiebehandeling moet gou na die diagnose van die siekte geskied, want so ' $n$ kind is 'n hoë risiko vir bloeding en infeksie. 'n Kombinasie van chemoterapeutiese middels is bewys beter te wees as enkele middels. Vincristine en hoë dosisse prednisoon word die meeste gebruik. Genoemde twee middels het min komplikasies, maar daar moet nogtans voor opgelet word.

Die siekte word in remissie beskou as aan die volgende kriteria voldoen word:

1. Die pasiënt moet sonder tekens en simptome van leukemie wees.

2. Die perifere witseltelling moet meer as 1500 selle per $\mathrm{mm}^{3}$ wees, hemoglobien meer as $12 \mathrm{gm}$ per liter, plaatjies meer as 150000 en daar moet geen blaste perifeer sirkuleer nie. 10.

3. Beenmurgaspiraat moet normale selulariteit toon met minder as $5 \%$ blaste.

By voldoening aan bogenoemde vereistes, kan met instandhoudingbehandeling voortgegaan word. Tydens dié fase word kombinasies van chemoterapeutiese middels vir tot vyf jaar genoem en soms word die behandeling met tye meer intensief gemaak om die remissie te verleng.

Direk na remissie word die brein en meninges bestraal, sodat die leukemiese selle wat daar is, gedood kan word. Chemoterapeutiese middels kruis die bloedbreinskans nie maklik nie, en daarom moet sekere van die middels ook intratekaal toegedien word. Indien 'n pasiënt 'n terugval sou hê, word die hele prosedure, soos hierbo beskryf, herhaal totdat remissie verkry is.

By hierdie siekte is groot vooruitgang in die behandeling gemaak, maar sonder ' $n$ multidissiplinêre benadering sal daar weinig sukses wees. 'n Hoë standaard van werk word van die klinikus, laboratorium en verpleegpersoneel vereis om die beste moontlike resultate te lewer.

\section{VERPLEGING VAN DIE LEUKEMIESE KIND}

\section{Spesiale verpleegsorg wat spesifiek betrekking het op die chemoterapeutiese middels wat gebruik word en hul newe-effekte:}

Die middels wat mees algemeen by kinders met leukemie gebruik word, sal vervolgens hieronder genoem word en daarby sal die belangrikste toksiese effekte van die middels bespreek word. Dit is baie belangrik dat die verpleegster wat hierdie pasiënte versorg bewus moet wees van die toksiese effekte, want sy moet oplet daarna, verligting van dié neweeffekte probeer bewerkstellig en permanente skade probeer voorkom by die meer ernstige newe-effekte.

- Vincristine _dit kan perifere neuropatie, miopatie en gebrekkige ingewandstonus met erge hardlywigheid gee. 


$\begin{array}{cc}\text { - Prednisoon en } & \text { hiper-irriteerbaarheid tot selfs } \\ \text { Prednisolone } & \text { psigose, hipertensie, peptiese } \\ & \text { ulserasie, vorgretensie, osteo- } \\ & \text { porose en immunodepressie kan } \\ & \text { voorkom. } \\ \text { - L-Asparaginase } & \text { anafilaktiese skok kan tydens } \\ & \text { toediening ontstaan asook } \\ & \text { hepatitis en pankreatitis. } \\ \text { - Daunarubicin } & \text { beenmurgonderdrukking en } \\ & \text { kardiotoksisiteit. } \\ \text { - Metotreksaat } & \text { beenmurgonderdrukking, lewer- } \\ & \text { toksisiteit orale en gastrointesti- } \\ & \text { nale ulserasies. } \\ \text { - 6-Mercaptopurine } & \text { beenmurgonderdrukking, soms } \\ & \text { skade aan slymvliese en lewer- } \\ & \text { skade. } \\ \text { - } & \text { sistitis en alopesie (verlies van } \\ & \text { hare). }{ }^{1, p} 96\end{array}$

\section{Die Verpleegster en observasies}

Vanaf opname, dwarsdeur die behandeling, tot en met ontslag is die verpleegster se observasies van uiterste belang vir die beste behandelingsplan van die pasient. Die verpleegster moet op haar hoede wees vir tekens en simptome wat manifestasies van die siekte is, byvoorbeeld bloedings (petechia, kneusings, hematurie), been- en buikpyn (tekens van leukemiese infiltrasie daar); psigiese toestand van die kind (hoofpyn, asook serebrale verlammings); styging in temperatuur, beweeglikheid van ledemate en algemene malaise. Die verpleegster moet ook oplet of die pasiënt spesifieke newe-effekte van sy spesifieke chemoterapeutiese middels ervaar, dit rapporteer en toepaslik behandel.

\section{Fisiese gemak}

Dit is baie belangrik dat die verpleegster sal sorg dat die pasiëntjies altyd so gemaklik moontlik gehou word. Bloedings van die mondslymvliese moet gou en effektief behandel word, sodat hulle nog gemaklik kan praat en eet. Hardlywigheid moet eerder voorkom as behandel word. Wanneer daar been- of gewrigbeserings is, moet die kind gemaklik geposisioneer word. Neusbloedings met beheer word sonder om die kind té opgestop en ongemaklik te laat voel. Ook selfs tydens uiters pynlike en ongemaklike prosedures, byvoorbeeld beenmurgpunksie en lumbaalpunksie moet die verpleegster vir die mees aangename, gemaklike, higiëniese

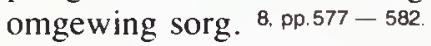

\section{Ontspanning}

Ontspanning, of beter gestel, inspanning, is ook van groot belang by dié kinders. Die verpleegster kan die arbeidsterapeut hierin betrek en haar bystaan deur 'n veilige omgewing aan die kind te voorsien. Die kind se aandag moet van sy siekte afgelei word en hy moet nie verveeld raak nie en die verpleegster moet aangaan met arbeidsterapeutiese aktiwiteite as die arbeidsterapeut nie daar is nie. Die kind moet egter ook genoeg rus gegun word en nie té veel uitgeput word nie.

\section{Eetpatroon}

Die kind met leukemie voel pap en siek en verder word hoë dosisse chemoterapeutiese middels aan hom toegedien en die twee faktore saam maak dat die kind glad nie lus voel om te eet nie. Die kinders het verlies van aptyt, is naar en verloor gevolglik gewig. Hierdie kinders moet 'n bietjie meer kilojoules en proteïne per massa kry as die hoeveelheid wat nodig is vir normale kinders 6 p 30 Voedsel waarvoor hulle lief is, moet spesiaal berei word. Dié kos moet ook te alle tye beskikbaar wees, want dikwels is hul aptyt beter of die naarheid is weg as dit nie etenstyd is nie. Verder moet spesiale maatreëls ook getref word by kinders wat byvoorbeeld sere in hul monde het — sagte of vloeibare diëte kan gegee word.

\section{Emosionele (psigiese) ondersteuning}

Die verpleegster is die persoon wat altyd by die pasiënt is - dag en nag - en dit is daarom ook sy wat op hierdie gebied die grootste bydrae maak. Die verpleegster moet die ouers so nou as moontlik by die behandelingsprogram betrek. Niemand beteken vir die kind soveel en kan die kind soveel ondersteun as sy ouers nie. Elke diagnostiese prosedure moet breedvoerig aan die ouers verduidelik word - ook die doel daarvan. Die ouers kan die kind dan weer só motiveer dat hy sy samewerking gee. Die ouers moet ook voel hulle is nuttig - hulle moet ook die kind help voer, help medisyne gee en met hom speel.

Die verpleegster moet 'n "maat" wees, maar ook 'n "ma" vir die kind, sy moet hom altyd aanvaar. Hy moet by haar kan huil, lag, veiligheid en gemak soek. Selfs in spesiale isolasie-eenhede moet sy die kind nie afsonder en geïsoleer laat voel nie. Haar spesiale klere mag haar nie in wese van die kind skei nie en sy moet daarvoor sorg.

Wanneer die kind terminaal siek is, moet sy nie minder aandag nie, maar juis meer aandag aan hom gee. Sy moet ook steun aan die ouers gee en wanneer nodig die hulp van andere, byvoorbeeld 'n predikant of maatskaplike werkster inroep.

\section{Isolasie en beskerming van die leukemiese pasiënt teen infeksies om optimale behandeling moontlik te maak.}

Die leukemiese pasiënt het dikwels, enersyds granulositopenie, en is dus baie gevoelig vir infeksies, en andersyds, as gevolg van chemoterapeutiese middels, het die pasiënt tydens die induksiefase van behandeling, geen weerstand nie. Hierdie pasiënt moet dus beskerm word teen infeksies, wat fataal mag wees, en omdat die pasiënt nie chemoterapie, wat vir die kankerpasiënt so belangrik is, kan ontvang wanneer hy 'n infeksie onderhede het nie.

Verskillende tipes isolasie bestaan, naamlik: 92 pp 234-241

1. Gewone saal-isolasie.

2. Laminêre-vloei-isolasie-eenhede.

3. "Life-Islands" - kajuite vir afsondering van die pasiënte.

1. Die gewone saal-isolasie blyk nie baie effektief te wees nie, aangesien die gewone hospitaalorganismes tog teenwoordig is. Personeel en besoekers dra altyd maklik siekte oor na die pasiënt, dus moet die pasiënt beskerm word teen indringers, hetsy besoekers, personeel of hospitaalorganismes.

2. Laminêre-vloei-isolasie eenhede is 'n baie effektiewe metode om die leukemiese pasiënt te beskerm. Die eenheid bestaan uit een of meer vertrekke waar lug, wat die eenheid binne kom eers gefiltreer word en dan net in een rigting vloei, en aan die teenoorgestelde kant van die 
vertrek uitgesuig word. Toegang tot die eenheid word verkry deur "n luglokval. Die eenheid maak dus nie direk na buite oop nie.

Alles in die eenheid word eers gesteriliseer deur gassterilisasiemetodes (wat mees effektief blyk te wees). Die eenheid is toegerus met al die geriewe wat die pasiënt mag benodig, asook 'n wasbak, wat voorsien word met steriele warm en koue water, en ander toiletgeriewe. Voedsel wat die eenheid binne kom, gaan eers deur 'n ultraviolet-steriliseerder voordat die pasiënt dit ontvang. Alles wat die pasiënt kry, of mee in aanraking kom, is dus kiemvry. Die ontkleclokaal vir personeel in die eenheid is ook in die luglokval area, sodat wanneer die personeel die pasiënt bereik, hulle in steriele klere geklee is

Lugmonsters van die eenheid toon 600 keer minder mikrobiese kontaminasie as in die gewone hospitaalkamer, en meer as $90 \%$ van die oppervlaktemonsters was steriel. 91, p 5

3. "Life-Islands" werk op byna dieselfde beginsel as bogenoemde eenhede, behalwe dat dit kleiner eenhede is en dat dit van politeen gemaak is. Lug word onder druk geplaas om vermenigvuldiging van mikrobe te beperk. Die kajuit bestaan uit ' $n$ bed wat omsluit is met 'n politeentent. Hierdie meganisme het 60 keer minder lug-mikrobiese kontaminasie as die gewone hospitaalkamers, sowel as $70 \%$ van die oppervlakte monsters is steriel. ${ }^{91, p 5}$ Die eenhede is mobiel en goedkoper, maar nie so duursaam as die laminêre-vloei-isolasie-eenhede nie. Die pasiënt kan sien wat in die res van die saal aangaan. Besoekers en personeel kan met die pasiënt kommunikeer op normale stemtoon, aangesien die eenheid nie klankdig is nie. Die pasiënt kan ook die verpleegster kontak met behulp van 'n klokkie en interkomstelsel.

In 'n poging om die gevaar van endogene patogene te verminder, word profilaktiese antibiotika-regimes uitgewerk vir die pasiënte, insluitende mondelingse middels om mond- en neusinfeksies te voorkom. Antibiotiese rome word aangewend aan die eksterne slymvliese en velvoue. Die pasiënte bad ook in antiseptiese seepoplossings.

Die tydperk van die streng omgekeerde isolasie is gewoonlik net tydens die induksiefase, wanneer die pasiënt akuut siek is, en duur ongeveer 4 tot 6 weke. Dit is dan veral in hierdie fase wat die pasiënt ondersteuning van beide sy ouers en die verplegingspersoneel benodig.

\section{Die kind met leukemie: Buite-pasiënt}

Wanneer die kind met leukemie goeie binnepasiëntsorg ontvang het, het hy nie 'n negatiewe houding oor sy buitepasiënt-besoek nie. So 'n kind se klinieksuster moet ook met hom 'n mooi vertrouensverhouding opbou, sodat hy die beste by sy behandeling baat. Die chemoterapieklinieksuster moet ook altyd met die ouers van die kind by behandeling bespreek en verduidelik, ook hoe sake met sy siekte staan. Die ouers sal dan ook hul volle samewerking en ondersteuning gee. 7.pp. 530-535.

Dit blyk duidelik dat alleen 'n span wat goed saamwerk 'n kind met leukenie effektief kan behandel, maar die verpleegster is een van die belangrikste lede van dié span en sy moet haar plek in die span behou deur op hoogte te bly van die nuutste ontwikkelings in die behandeling van die eertyds dodelike siekte.

\section{Dankbetuiging}

Graag wil die skryfsters hulle dank aan Dr. H.F. Oberholzer, Departement Chemoterapie, H.F. VerwoerdHospitaal uitspreek vir sy hulp en samewerking.

\section{BRONNELYS}

Boeke

1. Bouchard, R. en Owens, N.F. Nursing Care of the Cancer Patient, The C.V Mosby Company, Saint Louis 1972, pp. 9499.

2. Deeley, T.J., Fish. E.J. en Gough. M.A. A Guide to Oncological Nursing Livingstone Nursing Texts, Edinburgh 1974, pp. 134/40.

Latham, H.C., Heckel, R.V., Hebert, L.J. en Bennet, E. Paediatric Nursing. The C.V. Mosby Co. Saint Louis 1977, pp 506-511.

4. Jenkin. R.D.T. Management of Malignant Lymphoma in Childhood Modern Radiotherapy, Butterworth, London 1974, p. 319.

5. Mauer. Simoni. Current Status of the Treatment of Childhood Acute Lymphoblastic Leukaemia, Cancer Treatment Reviews III 1976 pp. 17-4I

6. Sherman, Mike. Feeding the Sick Chlld, U.S. Dept. of Health, Education and Welfare pp. 25-34.

7. Steele, Shirley, Nursing Care of the Child with Long-term Illness (2nd Edition), Appleton-Century-Crofts, New York 1977, pp.527-535

8. Waechter, E.H. en Blake, F.G. Nursing Care of Children (9th Edition) J.P. Lippincott, Philadelphia 1976, pp. 577-582.

Artikels

9. (1) Bodey, G.P. Reducing the Infection Hazard to Cancer Patients, Internis Observer, August 1971, p.5

(2) Levitan, A. A. The Use of an Isolator System in Cancer Chemotherapy, American Journal of Medicine Vol 44, February 1968, pp. 234-241.

10. Gegewens verkry van Departement Chemoterapie, H.F. Verwoerd-Hospitaal. 